\title{
A system dynamic model for measuring the construction quality of buildings' structures
}

\author{
Mehrdad Shokouh-Abdi $^{\mathrm{a}^{*}}$, Morteza Zahedi ${ }^{\mathrm{a}}$ and Ahmad Makui ${ }^{\mathrm{b}}$
}

${ }^{a}$ School of Civil Engineering, Iran University of Science and Technology, Narmak, Tehran, Iran

${ }^{a}$ School of Industrial Engineering, Iran University of Science and Technology, Narmak, Tehran, Iran

\begin{tabular}{l}
\hline A R T I C L E I N F O \\
\hline Article history: \\
Received October 102010 \\
Received in revised form \\
25 December 2010 \\
Accepted 30 December 2010 \\
Available online \\
3 January 2011 \\
\hline Keywords: \\
Dependence and feedback \\
Decision making trial and \\
evaluation laboratory \\
(DEMATEL) \\
System dynamic \\
Construction building \\
\hline
\end{tabular}

A B S T R A C T

\begin{abstract}
One of the most important issues on quality of building structure is its resistance against earthquake. Earthquake, as one of natural disasters, has been one of the main reasons of fatal incidents in developing countries. Any attempt to increase the quality of building structure could reduce any possible damages an earthquake could cause on society. This paper presents a system dynamic model to study the importance and behavior of the factors which affect the construction quality of buildings' structures. The proposed model of this paper is analyzed for a case study and the results are discussed. The paper also uses DEMATEL technique to compare the results of the proposed method. The paper concludes that among the whole factors which affect the construction quality of buildings' structures, the "performance of related organizations and institutions" is of the most important ones.
\end{abstract}

(C) 2011 Growing Science Ltd. All rights reserved.

\section{Introduction}

Structural quality is considered as one of the most important requirements in constructions. There are many evidences, which indicate that the quality of construction in many metropolitan cities is not at the desirable level. There are different reasons to blame the low quality of construction such as weaknesses in design and execution, use of non-standard materials, incorrect welding and joints, noncompliance with concrete implementation standards, etc. There are various methods to improve the quality of construction such as the implementation of total quality management (Arditi \& Gunaydin, 1997). An increase in quality of construction requires spending more expenditure. Abdelsalam and Gad (2009) studied the cost of quality on residential construction projects using preventionappraisal-failure technique to evaluate the cost of quality and to determine its optimum value for the residential construction projects in Dubai. The cost and time spent on a construction project normally involves the implementation of mathematical techniques where optimal solution cannot be achieved very easily. For instance, Zhang and Xing (2010) presented a fuzzy multi-objective model to find a trade-off between time and the cost of construction project. The resulted problem formulation was then solved using particle swarm optimization technique.

* Corresponding author. Tel:

E-mail addresses: m_shokouh_abdi@parsgc.com (M. Shoouh Abdi) 
One of the main reasons for blaming low quality construction is the lack of a good communication among the team members when a project is built. Leung (2008) proposed a real-time integrated communication system to monitor the progress and quality of construction works. In fact, site monitoring not only minimizes the construction defects and human flaws but also it can support project team members making strategic decisions in some important events.

Tehran, as a capital city of Iran, accommodates over 13 million people during the day and roughly about eight million people during the night. The city is highly populated and it suffers from different issues such as traffic jam, air pollution, low quality of construction, etc. Recently, there have been different studies performed by different governmental organizations about the consequence of an earthquake on this city. According to one the unpublished studies, an earthquake could result in the destruction of 500 thousand buildings, or $55 \%$ of total buildings and the death of 400 thousand people only in one of the regions called Ray located in sought part of Tehran. Another study examined 1284 buildings in Tehran municipality and reported that $18 \%$ suffered from design weakness, $42 \%$ from execution weakness and $40 \%$ from both. The other study determined more than 39 effective factors for privately constructed buildings of up to five stories. Although it is important to identify and classify the factors affecting the quality of structures, according to experts, making overall managerial decisions to promote construction quality is a tedious task based on a simple list of factors or assumptions. This paper presents system dynamic to analyze different factors influencing the quality of the construction. The proposed model of this paper uses different stages to determine the important factors influencing the quality of construction. In the first stage, we use a multiple criteria decision making (MCDM) method to determine the most important factors influencing the quality of construction. The MCDM method uses Delphi method to determine the influencing factors and then uses decision making trial and evaluation laboratory (DEMATEL) technique (Fontela \& Gabus ,1976) to rank the factors. The survey gathers 14 experts' feedbacks from different fields of governmental, academic, consultancy and construction fields of activities. In the second phase, we use system dynamic methodology to build a conceptual model based on the factors determined in the first phase.

This paper is organized as follows. We first present the conceptual system dynamic model in section 2. Section 3 presents the implementation of the proposed system dynamic and the sensitivity analysis of the proposed model is given in section 4. Finally, conclusion of the paper is given in the last part to summarize the contribution of the paper.

\section{The proposed method}

In this section, we present two phases of the proposed model of this paper. As explained earlier, we first need to determine the important factors affecting the quality of construction. The following summarizes the result of our survey on factors affecting the quality of construction,

A. Quality of materials (3 factors)

B. Performance of related people (according to law) (5 factors)

C. Performance of related organizations and institutions (according to law) (9 factors)

D. Quantity and Quality of regulations and technical documents (15 factors)

E. Quality at educational and cultural levels (factor 5)

F. Application of industrial construction (2 factors)

\subsection{Impact network affecting groups}

The impact network of affecting groups is depicted in Fig. 1. As we can observe from the figure, the parameters A, B,..., F not only influence the target parameter quality (Q) but also there are some influences among all these factors as well. Parameters A1, B1,.., F1 replace the original variables and have no independent identity and they are defined to facilitate the definition of the equations. 


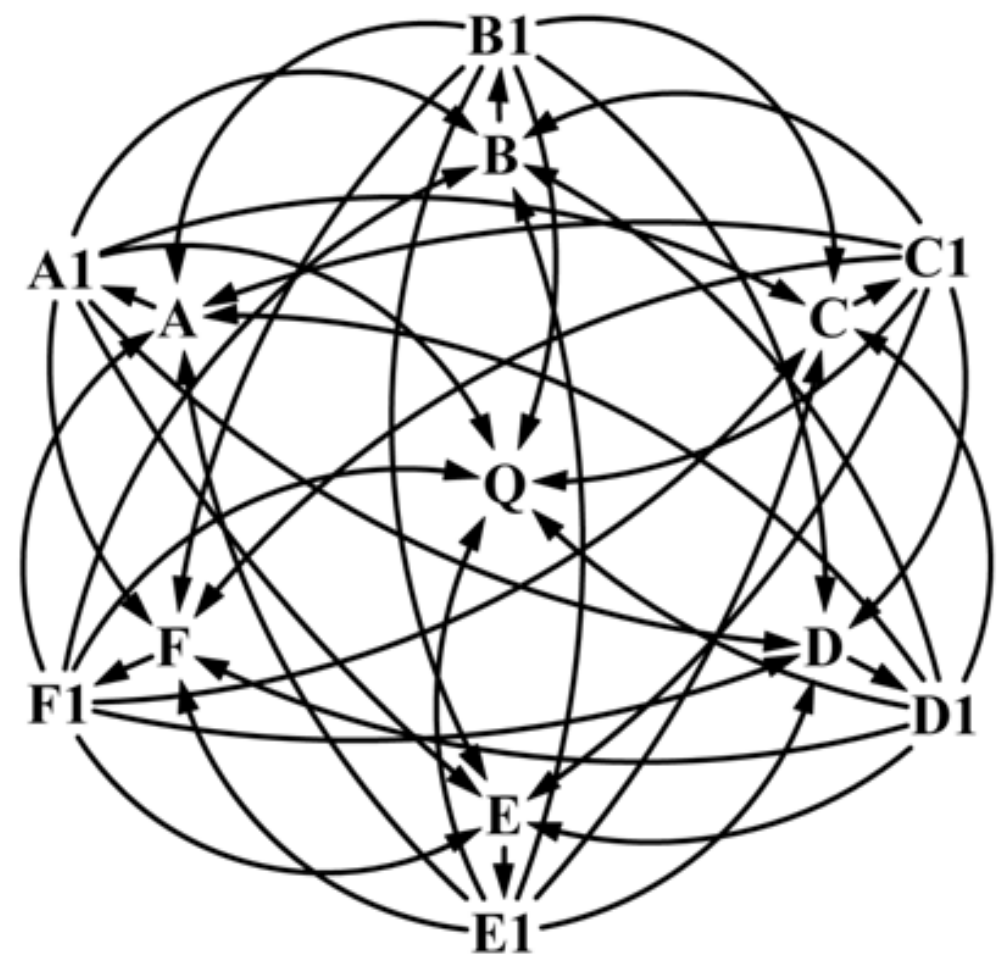

Fig. 1. The impact network of affecting groups on quality

\subsection{Mathematical model}

In order to gather the necessary information we first define three categories of good, moderate and bad for the factors affecting the quality of construction. In our survey, once we consider all possible scenarios, there are 729 possible cases for a single target parameters. Questioning experts to this extent for seven target parameters, for six groups plus quality parameter, obviously is not practical. Thus, a form was designed to reduce the number of cases while preserving the logical consistency of the subject to direct acceptable equations and manage the observers in a logical, systematic and gradual manner. The following cases were included in the questionnaire:

- All variables are "good", "moderate" or "bad": 3 cases

- One variable is "bad" and the others are "good": 6 cases

- One variable is "good" and the others are "bad": 6 cases

- Gradual change from "all good" to "all bad": 7 cases

- Gradual change as above with a different trend: 7 cases

- Gradual change from "all bad" to "all good": 7 cases

- Gradual change as above with a different trend: 7 cases

Although the number of the cases equals 43, eliminating duplicated cases to provide a logical arrangement for responses reduced the number of cases to 27. The experts evaluated the above cases in seven questionnaires, assigning parameters as "good", "moderate to high", "moderate", "moderate to low" and "bad". Quantitative values corresponding to the above options proceed from 0 to 1 at intervals of 0.25 . Table 1 shows the median of the results of the survey. 
Table 1

A sample of one table collecting experts' feedbacks

\begin{tabular}{|c|c|c|c|c|c|c|c|c|c|c|c|c|c|c|}
\hline \multirow{2}{*}{$\begin{array}{l}0 \\
\stackrel{0}{0} \\
\frac{0}{0} \\
0\end{array}$} & \multirow{2}{*}{$\begin{array}{l}\infty \\
\text { D. } \\
\stackrel{D}{0} . \\
0 .\end{array}$} & \multirow[b]{2}{*}{ E } & \multirow[b]{2}{*}{$\mathrm{C}$} & \multirow[b]{2}{*}{$\mathrm{D}$} & \multirow[b]{2}{*}{ F } & \multirow[b]{2}{*}{ A } & \multirow[b]{2}{*}{$\mathrm{Z}^{*}$} & \multicolumn{7}{|c|}{$\begin{array}{c}\text { B } \\
\text { Performance of related persons (according to law) }\end{array}$} \\
\hline & & & & & & & & 1 & 2 & 3 & 4 & 5 & median & mean \\
\hline 1 & 1 & good & good & good & good & good & good & 1 & 1 & 1 & 1 & 1 & 1 & 1 \\
\hline 2 & 2 & moderate & moderate & moderate & moderate & moderate & moderate & 0.75 & 0.5 & 0.5 & 0.5 & 0.5 & 0.5 & 0.55 \\
\hline 3 & 3 & bad & bad & bad & bad & bad & bad & 0.25 & 0 & 0 & 0 & 0 & 0 & 0.05 \\
\hline 4 & 4 & bad & good & good & good & good & good & 0.5 & 0.5 & 0.75 & 0 & 0.75 & 0.5 & 0.5 \\
\hline 5 & 5 & good & bad & good & good & good & good & 1 & 0.75 & 0.5 & 0.5 & 0.25 & 0.5 & 0.6 \\
\hline 6 & 6 & good & good & bad & good & good & good & 0.75 & 0.75 & 0.5 & 0.5 & 0.5 & 0.5 & 0.6 \\
\hline 7 & 7 & good & good & good & bad & good & good & 1 & 0.75 & 0.5 & 0.25 & 0.75 & 0.75 & 0.65 \\
\hline 8 & 8 & good & good & good & good & bad & good & 1 & 0.75 & 0.5 & 0 & 0.75 & 0.75 & 0.6 \\
\hline 9 & 9 & good & Good & good & good & good & bad & 1 & 0.75 & 1 & 0.25 & 0.5 & 0.75 & 0.7 \\
\hline 10 & 10 & good & $\mathrm{Bad}$ & bad & bad & bad & bad & 0.75 & 0.5 & 0 & 0 & 0 & 0 & 0.25 \\
\hline 11 & 11 & bad & Good & bad & bad & bad & bad & 0.5 & 0.25 & 0 & 0 & 0.25 & 0.25 & 0.2 \\
\hline 12 & 12 & bad & $\mathrm{Bad}$ & good & bad & bad & bad & 0.5 & 0.25 & 0 & 0 & 0 & 0 & 0.15 \\
\hline 13 & 13 & bad & Bad & bad & good & bad & bad & 0.5 & 0.25 & 0 & 0 & 0 & 0 & 0.15 \\
\hline 14 & 14 & bad & Bad & bad & bad & good & bad & 0.25 & 0.25 & 0 & 0 & 0.25 & 0.25 & 0.15 \\
\hline 15 & 15 & bad & Bad & bad & bad & bad & good & 0.25 & 0.25 & 0 & 0 & 0.5 & 0.25 & 0.2 \\
\hline
\end{tabular}

*All other options

\subsection{Regression results}

In order to analyze the relationship among different variables $A, B, C, D, F$ and $Z$ we use logistic regressions. We have performed all possible regression analysis among the variables which would be used as input factors for the proposed system dynamic. Table 2 shows some of the results of the implementation of regression analysis.

\section{Table 2}

The results of logistic regressions for $\mathrm{A}$ and $\mathrm{Q}$ in terms of other variables

$\mathrm{A}(1)=0.489+0.106 \mathrm{C}+0.0821 \mathrm{E}+0.0979 \mathrm{D}+0.0594 \mathrm{~F}+0.140 \mathrm{~B}-0.0201 \mathrm{Z}$

$A(2)=0.0726+0.134 \mathrm{C}+0.155 \mathrm{E}+0.112 \mathrm{D}+0.166 \mathrm{~F}+0.179 \mathrm{~B}+0.132 \mathrm{Z}$

$\mathrm{A}(3)=-0.0715+0.285 \mathrm{C}+0.148 \mathrm{E}+0.182 \mathrm{D}+0.0798 \mathrm{~F}+0.0124 \mathrm{~B}+0.308 \mathrm{Z}$

$\mathrm{A}(4)=-0.0110+0.267 \mathrm{C}+0.200 \mathrm{E}+0.282 \mathrm{D}+0.0518 \mathrm{~F}-0.0743 \mathrm{~B}+0.0178 \mathrm{Z}$

$\mathrm{A}(5)=0.175+0.250 \mathrm{C}+0.0162 \mathrm{E}+0.0649 \mathrm{D}-0.0065 \mathrm{~F}+0.159 \mathrm{~B}+0.0158 \mathrm{Z}$

$\mathrm{A}($ Med5 $)=0.0403+0.258 \mathrm{C}+0.158 \mathrm{E}+0.124 \mathrm{D}+0.0898 \mathrm{~F}+0.110 \mathrm{~B}+0.121 \mathrm{Z}$

$\mathrm{A}($ Ave5) $=0.130+0.208 \mathrm{C}+0.119 \mathrm{E}+0.142 \mathrm{D}+0.0757 \mathrm{~F}+0.0853 \mathrm{~B}+0.0880 \mathrm{Z}$

$\mathrm{Q}(1)=0.129+0.0960 \mathrm{C}+0.221 \mathrm{~B}+0.161 \mathrm{E}+0.0502 \mathrm{D}+0.0392 \mathrm{~F}+0.174 \mathrm{~A}$

$Q(2)=0.0764+0.0960 \mathrm{C}+0.300 \mathrm{~B}+0.105 \mathrm{E}+0.118 \mathrm{D}+0.119 \mathrm{~F}+0.0863 \mathrm{~A}$

$\mathrm{Q}(3)=-0.0626+0.0623 \mathrm{C}+0.331 \mathrm{~B}+0.0121 \mathrm{E}+0.217 \mathrm{D}+0.233 \mathrm{~F}+0.141 \mathrm{~A}$

$\mathrm{Q}(4)=-0.115+0.0244 \mathrm{C}+0.353 \mathrm{~B}+0.137 \mathrm{E}+0.194 \mathrm{D}+0.0131 \mathrm{~F}+0.138 \mathrm{~A}$

$\mathrm{Q}(5)=0.0033+0.133 \mathrm{C}+0.403 \mathrm{~B}-0.0200 \mathrm{E}+0.142 \mathrm{D}-0.0376 \mathrm{~F}+0.245 \mathrm{~A}$

$\mathrm{Q}($ Med5) $=0.0330+0.0638 \mathrm{C}+0.338 \mathrm{~B}+0.0383 \mathrm{E}+0.190 \mathrm{D}+0.0979 \mathrm{~F}+0.124 \mathrm{~A}$

$\mathrm{Q}($ Ave5) $=0.0062+0.0823 \mathrm{C}+0.322 \mathrm{~B}+0.0790 \mathrm{E}+0.144 \mathrm{D}+0.0732 \mathrm{~F}+0.157 \mathrm{~A}$

As we can see from Table 2 quality can be described as other influencing factors of $A, B, C, D, E$ and $Z$. We can also see there are some variations in coefficients as a results of the medians and averages of the experts' feedback were significant in some cases. In the further analyses based on this feedback, the median parameter was used to remove the effect of extremes. Next, we explain the details of our finding. 


\subsubsection{Group A: quality of materials}

Group A, expert feedback regarding the quality of materials, produced an equation pertaining to the median feedback as:

$\mathrm{A}($ Med5 $)=0.0403+0.258 \mathrm{C}+0.158 \mathrm{E}+0.124 \mathrm{D}+0.0898 \mathrm{~F}+0.110 \mathrm{~B}+0.121 \mathrm{Z}$.

According to Eq. (1), group $\mathrm{C}$ has the highest influencing factor with an impact factor of 0.258 , which represents $30 \%$ coefficient weights of all variables. The other most influencing factors were E, $\mathrm{D}, \mathrm{Z}$ and $\mathrm{B}$.

\subsubsection{Group B: Performance of related people}

The logistic regression model for group B is as follows,

$\mathrm{B}(\mathrm{Med} 5)=0.0018+0.174 \mathrm{E}+0.272 \mathrm{C}+0.164 \mathrm{D}+0.0107 \mathrm{~F}+0.128 \mathrm{~A}+0.131 \mathrm{Z}$.

Once again, group C, with an impact factor of 0.272 , or a $31 \%$ weight coefficient has the most impact on group B. After C, groups E and D with $20 \%$ and $19 \%$ weight coefficients, respectively, have the greatest effects on group B. groups Z and A with 15\% weight coefficients are next. Group $\mathrm{F}$ has a minimum impact with a rate of $1 \%$. Group $\mathrm{Z}$ in this case included job satisfaction, total cost of living, spiritual commitment, and cost-income ratio.

\subsubsection{Group C: Performance of related organizations and institutions}

The relationship of the median expert feedback to group C, performance of organizations and institutes according to code, is as follows:

$C($ Med5 $)=-0.0464+0.344 \mathrm{D}+0.157 \mathrm{~B}+0.0329 \mathrm{E}+0.100 \mathrm{~F}+0.117 \mathrm{~A}+0.214 \mathrm{Z}$.

Group C was primarily under the influence of group D with about a 36\% weight coefficient. The weights for groups $\mathrm{Z}$ and $\mathrm{B}$ follow group D were at $22 \%$ and $16 \%$, respectively. Groups A and F had, respectively, $12 \%$ and $10 \%$ influence. Group $\mathrm{E}$ had the lowest impact at 3\%. Group Z included acceptance by parliament, international organizations or manufacturers and the behavior of officials, social justice, job satisfaction, family cost portfolio, spiritual commitment and cost-income ratio.

\subsubsection{Group D: Quantity and quality of regulations and technical documents}

Group D, quantity and effectiveness of regulations and technical documents associated with expert feedback is as follows,

$D($ Med5 $)=0.0394+0.688 C-0.0519 B+0.105 E+0.0959 F+0.0287 A+0.0559 Z$.

In addition to the major impact of $\mathrm{D}$ on $\mathrm{C}$, group $\mathrm{D}$ was also highly affected, $71 \%$ positive weight coefficients, by group C. This indicates an interactive relationship between these two important parameters. The influence of groups $\mathrm{E}$ and $\mathrm{F}$ followed in impact at $11 \%$ and $10 \%$, respectively. Groups Z, B, and A had no significant effect on D.

\subsubsection{Group E: Quality at educational and cultural levels}

Group E, quality at educational and cultural levels, had an expert feedback median as follows:

$\mathrm{E}(\mathrm{Med} 5)=0.0034+0.432 \mathrm{C}+0.149 \mathrm{D}+0.0406 \mathrm{~F}+0.138 \mathrm{~B}+0.0117 \mathrm{~A}+0.233 \mathrm{Z}$.

Group C primarily influenced group E, quality at educational and cultural levels with a 43\% weight coefficient. Groups Z at 23\%, D at 15\% and B at 14\% followed this. Experts included media, global 
cultural and scientific relations, general education, social welfare, scientific progress, and social improvement in group Z as other important factors. Groups $\mathrm{F}$ and $\mathrm{A}$ had no major impact on E.

\subsubsection{Group F: Application of industrial construction}

Group F, application of industrial construction, equation is as follows:

$F($ Med5 $)=0.0522+0.364 \mathrm{C}+0.133 \mathrm{E}+0.0439 \mathrm{~B}+0.167 \mathrm{D}+0.0003 \mathrm{~A}+0.129 \mathrm{Z}$

Once again, group C, with an impact factor of 43\%, had the most influence on F. Groups D, E, and Z followed with, respectively, 20\%, 16\% and 15\%. Experts included domestic industrial and economic status, production, government policy, cost-profit analysis, banking system cooperation, customs policies, work regulations and insurance in group Z. Group B had no significant effect on Group F.

\subsubsection{Parameter Q: Quality of construction}

The relationship of target parameter Q, quality of construction, was as follows:

$\mathrm{Q}($ Med5 $)=0.0330+0.0638 \mathrm{C}+0.338 \mathrm{~B}+0.0383 \mathrm{E}+0.190 \mathrm{D}+0.0979 \mathrm{~F}+0.124 \mathrm{~A}$

Apart from interaction parameters, discussed previously, the following groups in order of ranking influenced target parameter Q,
B: $40 \%$
D: $22 \%$
A: $15 \%$
F: $11 \%$
C: $7 \%$
E: $5 \%$.

It is considered that group B with $40 \%$ effectiveness, has the most effect on Q. Ranking 2 belongs to group D with 22\% effectiveness. Rankings 3 and 4 with $15 \%$ and $11 \%$ effectiveness, respectively, belong to groups $\mathrm{A}$ and $\mathrm{F}$ with almost the same level of importance. Rankings 5 and 6 with 7\% and $5 \%$ effectiveness coefficients, respectively, were considered to be of the same level of importance and belong to $\mathrm{C}$ and $\mathrm{E}$ groups.

\subsection{Initial values of variables and delay time}

Initial values of the variables were chosen as shown in Table 3. The selection of values was based on overall expert feedback during the analysis. The results of the step-by-step process and a comparison of the final results had no significant effects.

\section{Table 3}

Initial values of variables (effective groups)

\begin{tabular}{clc}
\hline Group & Title & Initial Value \\
\hline A & Quality of materials & 70 \\
B & Performance of related persons (according to law) & 40 \\
C & Performance of related organizations and institutions (according to law) & 50 \\
D & Quantity and Quality of regulations and technical documents & 70 \\
E & Quality at educational and cultural levels & 60 \\
F & Application of industrial construction & 50 \\
Z & Other effective parameters & 100 \\
\hline
\end{tabular}

The length of delay affecting a parameter was considered to be a fixed rate of 6 months for all variables. Although delay time had no effect in comparison with the results, it does indicate the gradual change in variables in a more tangible form. 


\section{The system dynamics model analysis}

In this section, we present the implementation of system dynamic model using the information achieved from the previous section. The structure of system dynamic framework is shown on Fig 1. The implementation was performed using Vensim software package (Sterman, 2000), which is dedicated for the analysis of system dynamic models. We also used experts' suggestions on revising the model and provided some managerial implications. The following delay fixed functions were used for the implementation of our system dynamic modeling.

$$
\begin{aligned}
\mathrm{A}= & \mathrm{DELAY} \text { FIXED }(0.0403 * 100+0.258 * \mathrm{C} 1+0.158 * \mathrm{E} 1+0.124 * \mathrm{D} 1+0.0898 * \mathrm{~F} 1+0.11 * \\
& \mathrm{B} 1+0.121 * 100,6, \mathrm{Aini}) \\
\mathrm{B}= & \mathrm{DELAY} \mathrm{FIXED}(0.0018 * 100+0.174 * \mathrm{E} 1+0.272 * \mathrm{C} 1+0.164 * \mathrm{D} 1+0.0107 * \mathrm{~F} 1+0.128 * \\
& \mathrm{A} 1+0.131 * 100,6, \mathrm{Bini}) \\
\mathrm{C}= & \mathrm{DELAY} \mathrm{FIXED}(-0.0464 * 100+0.344 * \mathrm{D} 1+0.157 * \mathrm{~B} 1+0.0329 * \mathrm{E} 1+0.1 * \mathrm{~F} 1+0.117 * \\
& \mathrm{A} 1+0.214 * 100,6, \mathrm{Cini}) \\
\mathrm{D}= & \mathrm{DELAY} \mathrm{FIXED}(0.0394 * 100+0.688 * \mathrm{C} 1-0.0519 * \mathrm{~B} 1+0.105 * \mathrm{E} 1+0.0959 * \mathrm{~F} 1+0.0287 \\
& * \text { A1 }+0.0559 * 100,6, \mathrm{Dini}) \\
\mathrm{E}= & \mathrm{DELAY} \mathrm{FIXED}(0.0034 * 100+0.432 * \mathrm{C} 1+0.149 * \mathrm{D} 1+0.0406 * \mathrm{~F} 1+0.138 * \mathrm{~B} 1+0.0117 \\
& * \mathrm{~A} 1+0.233 * 100,6, \mathrm{Eini}) \\
\mathrm{F}= & \mathrm{DELAY} \mathrm{FIXED}(0.0522 * 100+0.364 * \mathrm{C} 1+0.133 * \mathrm{E} 1+0.0439 * \mathrm{~B} 1+0.167 * \mathrm{D} 1+0.0003 \\
& * \text { A } 1+0.129 * 100,6, \mathrm{Fini}) \\
\mathrm{Q}= & 0.033 * 100+0.0638 * \mathrm{C} 1+0.338 * \mathrm{~B} 1+0.0383 * \mathrm{E} 1+0.19 * \mathrm{D} 1+0.0979 * \mathrm{~F} 1+0.124 * \mathrm{~A} 1
\end{aligned}
$$

The MIN function was used to control the quantity of variables not exceeding 100 as A1 = MIN (A, 100). The MIN function was defined similarly for other groups. Table 4 summarizes the results of our implementation based on expert feedback median. The following conclusions were made based on the results:

- The system dynamic model calculated values based on numerical analysis; the quantity of each variable in every cycle was determined compared with other variables in the previous analysis cycle, which was controlled manually.

- The values of all variables changed in different cycles and gradually converged to their ultimate values. These changes, especially in the primary cycles, could fluctuate.

- The ultimate values of variables created a balance that could not be changed. Assuming the accuracy of the integers, balance was achieved at $\mathrm{T}=150$.

\section{Sensitivity analysis of system dynamics model}

In this section, we perform sensitivity analysis on the data based on expert median feedback. We have found different scenarios for our proposed model, which are as follows,

- Initial values: 1 case

- Balance status: 1 case

- One variable in ultimate state: 6 cases

- Several variables in ultimate state: 8 cases

- $10 \%$ reduction from original value: 7 cases

- One variable equals zero: 6 cases

- $10 \%$ sequential and increase in basic value up to a final value: 19 cases

- Gradual increase in variables with initial value close to ultimate, from zero: 10 cases

- Total cases studied: 58 cases 


\section{Table 4}

Model analysis for initial values

\begin{tabular}{|c|c|c|c|c|c|c|c|}
\hline Time (Month) & A & B & $\mathrm{C}$ & $\mathrm{D}$ & $\mathrm{E}$ & $\mathrm{F}$ & $\mathrm{Q}$ \\
\hline 0 & 70.0000 & 40.0000 & 50.0000 & 70.0000 & 60.0000 & 50.0000 & 49.1830 \\
\hline 6 & 56.0800 & 58.2950 & 62.2840 & 54.9580 & 64.0390 & 57.7670 & 52.4814 \\
\hline 12 & 60.7322 & 58.1735 & 59.2628 & 63.2293 & 69.7816 & 61.0625 & 54.9386 \\
\hline 18 & 62.1682 & 60.3382 & 63.1519 & 62.2096 & 69.8804 & 62.104 & 56.0085 \\
\hline 24 & 63.3924 & 61.4409 & 63.4163 & 64.9244 & 71.7663 & 63.4579 & 57.2704 \\
\hline 30 & 64.3381 & 62.4574 & 64.864 & 65.4121 & 72.5065 & 64.3071 & 58.0278 \\
\hline 36 & 65.0771 & 63.1901 & 65.4113 & 66.5416 & 73.3904 & 65.0589 & 58.7241 \\
\hline 42 & 65.6462 & 63.7806 & 66.1056 & 67.0663 & 73.9354 & 65.5967 & 59.2118 \\
\hline 48 & 66.0897 & 64.229 & 66.5171 & 67.6384 & 74.4235 & 66.0356 & 59.6149 \\
\hline 54 & 66.4327 & 64.5811 & 66.8962 & 68.0043 & 74.7714 & 66.3657 & 59.9158 \\
\hline 60 & 66.6992 & 64.8522 & 67.1619 & 68.3249 & 75.0557 & 66.6266 & 60.1548 \\
\hline 66 & 66.9057 & 65.0634 & 67.3813 & 68.5562 & 75.2694 & 66.8266 & 60.3375 \\
\hline 72 & 67.0659 & 65.2268 & 67.5453 & 68.7437 & 75.4383 & 66.9829 & 60.4804 \\
\hline 78 & 67.1902 & 65.3537 & 67.6754 & 68.8853 & 75.5678 & 67.1036 & 60.5907 \\
\hline 84 & 67.2866 & 65.452 & 67.7749 & 68.997 & 75.669 & 67.1974 & 60.6765 \\
\hline 90 & 67.3613 & 65.5284 & 67.8527 & 69.0828 & 75.7472 & 67.2701 & 60.743 \\
\hline 96 & 67.4193 & 65.5876 & 67.9128 & 69.1497 & 75.8079 & 67.3265 & 60.7946 \\
\hline 102 & 67.4643 & 65.6335 & 67.9595 & 69.2014 & 75.855 & 67.3702 & 60.8346 \\
\hline 108 & 67.4991 & 65.6691 & 67.9957 & 69.2416 & 75.8915 & 67.4042 & 60.8656 \\
\hline 114 & 67.5262 & 65.6967 & 68.0238 & 69.2727 & 75.9198 & 67.4305 & 60.8896 \\
\hline 120 & 67.5472 & 65.7181 & 68.0456 & 69.2969 & 75.9418 & 67.4509 & 60.9083 \\
\hline 126 & 67.5635 & 65.7347 & 68.0625 & 69.3156 & 75.9588 & 67.4667 & 60.9228 \\
\hline 132 & 67.5761 & 65.7476 & 68.0756 & 69.3302 & 75.972 & 67.479 & 60.9340 \\
\hline 138 & 67.5859 & 65.7576 & 68.0857 & 69.3414 & 75.9823 & 67.4885 & 60.9427 \\
\hline 144 & 67.5935 & 65.7653 & 68.0936 & 69.3502 & 75.9902 & 67.4959 & 60.9495 \\
\hline 150 & 67.5993 & 65.7714 & 68.0997 & 69.3569 & 75.9964 & 67.5016 & 60.9547 \\
\hline 156 & 67.6039 & 65.776 & 68.1045 & 69.3622 & 76.0012 & 67.5061 & 60.9588 \\
\hline 162 & 67.6075 & 65.7796 & 68.1081 & 69.3663 & 76.0049 & 67.5095 & 60.9619 \\
\hline 168 & 67.6102 & 65.7824 & 68.1110 & 69.3694 & 76.0078 & 67.5122 & 60.9643 \\
\hline 174 & 67.6123 & 65.7846 & 68.1132 & 69.3719 & 76.0100 & 67.5143 & 60.9662 \\
\hline 180 & 67.614 & 65.7863 & 68.1149 & 69.3738 & 76.0117 & 67.5159 & 60.9677 \\
\hline 186 & 67.6153 & 65.7876 & 68.1162 & 69.3753 & 76.0131 & 67.5171 & 60.9689 \\
\hline 192 & 67.6163 & 65.7886 & 68.1173 & 69.3764 & 76.0141 & 67.5181 & 60.9697 \\
\hline 198 & 67.6170 & 65.7894 & 68.1181 & 69.3773 & 76.0149 & 67.5188 & 60.9704 \\
\hline 204 & 67.6176 & 65.7900 & 68.1187 & 69.378 & 76.0156 & 67.5194 & 60.9710 \\
\hline 210 & 67.6181 & 65.7905 & 68.1192 & 69.3785 & 76.016 & 67.5199 & 60.9714 \\
\hline 216 & 67.6185 & 65.7909 & 68.1196 & 69.379 & 76.0164 & 67.5202 & 60.9717 \\
\hline 222 & 67.6187 & 65.7912 & 68.1199 & 69.3793 & 76.0167 & 67.5205 & 60.9719 \\
\hline 228 & 67.619 & 65.7914 & 68.1201 & 69.3795 & 76.0169 & 67.5207 & 60.9721 \\
\hline 234 & 67.6191 & 65.7915 & 68.1203 & 69.3797 & 76.0171 & 67.5209 & 60.9723 \\
\hline 240 & 67.6193 & 65.7917 & 68.1204 & 69.3799 & 76.0173 & 67.521 & 60.9724 \\
\hline
\end{tabular}

In order to perform the sensitivity analysis we need to define a fixed measuring index. Therefore, we have used TQu and TSt as time to achieve ultimate quality and balanced status, respectively. In each case, the results derived from system dynamics were reviewed in different cycles from zero to 240 months at intervals of 6 months and the times to achieve TQu and TSt were determined. A summary of the results carried out for the 58 are described in Table 5. 
Table 5

Summary of the results for the sensitivity analysis of system dynamics model

\begin{tabular}{|c|c|c|c|c|c|c|c|c|c|c|c|}
\hline \multirow{2}{*}{$\begin{array}{l}\text { Case } \\
\text { Description }\end{array}$} & \multirow{2}{*}{ A } & \multirow{2}{*}{ B } & \multirow{2}{*}{$\mathrm{C}$} & \multirow{2}{*}{$\mathrm{D}$} & \multirow{2}{*}{$\mathrm{E}$} & \multirow{2}{*}{$\mathrm{F}$} & \multirow{2}{*}{ Z } & \multirow{2}{*}{ Q0 } & \multicolumn{2}{|c|}{$\mathrm{Qu}$} & \multirow[t]{2}{*}{ TSt } \\
\hline & & & & & & & & & value & TQu & \\
\hline Initial values & 70 & 40 & 50 & 70 & 60 & 50 & 100 & 49 & 61 & 78 & 150 \\
\hline Balance status & 68 & 66 & 68 & 69 & 76 & 68 & 100 & 61 & 61 & 0 & 12 \\
\hline \multirow{6}{*}{$\begin{array}{l}\text { One variable in } \\
\text { ultimate state }\end{array}$} & 68 & 40 & 50 & 70 & 60 & 50 & 100 & 49 & \multirow{6}{*}{61} & 78 & 150 \\
\hline & 70 & 66 & 50 & 70 & 60 & 50 & 100 & 58 & & 72 & 144 \\
\hline & 70 & 40 & 68 & 70 & 60 & 50 & 100 & 50 & & 54 & 132 \\
\hline & 70 & 40 & 50 & 69 & 60 & 50 & 100 & 49 & & 78 & 150 \\
\hline & 70 & 40 & 50 & 70 & 76 & 50 & 100 & 50 & & 72 & 150 \\
\hline & 70 & 40 & 50 & 70 & 60 & 68 & 100 & 51 & & 72 & 150 \\
\hline & 70 & 66 & 50 & 70 & 76 & 68 & 100 & 60 & & 60 & 138 \\
\hline & 70 & 66 & 68 & 70 & 60 & 50 & 100 & 59 & & 42 & 120 \\
\hline & 70 & 40 & 68 & 70 & 76 & 50 & 100 & 51 & & 48 & 126 \\
\hline Several & 70 & 40 & 68 & 70 & 60 & 68 & 100 & 52 & & 48 & 126 \\
\hline variables in & 70 & 66 & 68 & 70 & 76 & 50 & 100 & 60 & 61 & 24 & 96 \\
\hline & 70 & 66 & 68 & 70 & 60 & 68 & 100 & 61 & & 24 & 96 \\
\hline & 70 & 40 & 68 & 70 & 76 & 68 & 100 & 53 & & 30 & 108 \\
\hline & 70 & 66 & 68 & 70 & 76 & 68 & 100 & 61 & & 0 & 30 \\
\hline & 63 & 40 & 50 & 70 & 60 & 50 & 100 & 48 & & 78 & 150 \\
\hline & 70 & 36 & 50 & 70 & 60 & 50 & 100 & 48 & & 78 & 150 \\
\hline $10 \%$ reduction & 70 & 40 & 45 & 70 & 60 & 50 & 100 & 49 & & 78 & 156 \\
\hline from original & 70 & 40 & 50 & 63 & 60 & 50 & 100 & 48 & 61 & 78 & 156 \\
\hline value & 70 & 40 & 50 & 70 & 54 & 50 & 100 & 49 & & 78 & 150 \\
\hline & 70 & 40 & 50 & 70 & 60 & 45 & 100 & 49 & & 78 & 150 \\
\hline & 63 & 40 & 50 & 63 & 60 & 50 & 100 & 47 & & 48 & 156 \\
\hline & 0 & 40 & 50 & 70 & 60 & 50 & 100 & 41 & & 84 & 162 \\
\hline & 70 & 0 & 50 & 70 & 60 & 50 & 100 & 36 & & 84 & 156 \\
\hline One variable & 70 & 40 & 0 & 70 & 60 & 50 & 100 & 46 & & 96 & 174 \\
\hline equals zero & 70 & 40 & 50 & 0 & 60 & 50 & 100 & 36 & 61 & 96 & 174 \\
\hline & 70 & 40 & 50 & 70 & 0 & 50 & 100 & 47 & & 84 & 162 \\
\hline & 70 & 40 & 50 & 70 & 60 & 0 & 100 & 44 & & 84 & 156 \\
\hline & 68 & 40 & 50 & 69 & 60 & 50 & 100 & 49 & & 78 & 150 \\
\hline & 68 & 40 & 55 & 69 & 60 & 50 & 100 & 49 & & 72 & 150 \\
\hline & 68 & 40 & 60 & 69 & 60 & 50 & 100 & 49 & & 66 & 144 \\
\hline & 68 & 40 & 65 & 69 & 60 & 50 & 100 & 50 & & 60 & 138 \\
\hline & 68 & 40 & 68 & 69 & 60 & 50 & 100 & 50 & & 60 & 132 \\
\hline & 68 & 44 & 50 & 69 & 60 & 50 & 100 & 50 & & 78 & 150 \\
\hline & 68 & 48 & 50 & 69 & 60 & 50 & 100 & 51 & & 78 & 150 \\
\hline & 68 & 52 & 50 & 69 & 60 & 50 & 100 & 53 & & 72 & 150 \\
\hline $10 \%$ sequential & 68 & 56 & 50 & 69 & 60 & 50 & 100 & 54 & & 72 & 150 \\
\hline and increase in & 68 & 60 & 50 & 69 & 60 & 50 & 100 & 56 & 61 & 72 & 150 \\
\hline basic value up & 68 & 64 & 50 & 69 & 60 & 50 & 100 & 57 & & 72 & 150 \\
\hline & 68 & 66 & 50 & 69 & 60 & 50 & 100 & 58 & & 72 & 144 \\
\hline & 68 & 40 & 50 & 69 & 60 & 55 & 100 & 49 & & 78 & 150 \\
\hline & 68 & 40 & 50 & 69 & 60 & 60 & 100 & 50 & & 72 & 150 \\
\hline & 68 & 40 & 50 & 69 & 60 & 65 & 100 & 50 & & 72 & 150 \\
\hline & 68 & 40 & 50 & 69 & 60 & 68 & 100 & 51 & & 72 & 150 \\
\hline & 68 & 40 & 50 & 69 & 66 & 50 & 100 & 49 & & 78 & 150 \\
\hline & 68 & 40 & 50 & 69 & 72 & 50 & 100 & 49 & & 72 & 150 \\
\hline & 68 & 40 & 50 & 69 & 76 & 50 & 100 & 49 & & 72 & 150 \\
\hline & 0 & 40 & 50 & 70 & 60 & 50 & 100 & 41 & & 84 & 162 \\
\hline & 20 & 40 & 50 & 70 & 60 & 50 & 100 & 43 & & 84 & 156 \\
\hline Gradual & 40 & 40 & 50 & 70 & 60 & 50 & 100 & 45 & & 78 & 156 \\
\hline increase in & 60 & 40 & 50 & 70 & 60 & 50 & 100 & 48 & & 78 & 150 \\
\hline variables with & 68 & 40 & 50 & 70 & 60 & 50 & 100 & 49 & & 78 & 150 \\
\hline initial value & 70 & 40 & 50 & 0 & 60 & 50 & 100 & 36 & 61 & 96 & 174 \\
\hline $\begin{array}{l}\text { close to } \\
\text { from }\end{array}$ & 70 & 40 & 50 & 20 & 60 & 50 & 100 & 40 & & 90 & 168 \\
\hline ultimate, from & 70 & 40 & 50 & 40 & 60 & 50 & 100 & 43 & & 84 & 162 \\
\hline & 70 & 40 & 50 & 60 & 60 & 50 & 100 & 47 & & 78 & 156 \\
\hline & 70 & 40 & 50 & 69 & 60 & 50 & 100 & 49 & & 78 & 150 \\
\hline
\end{tabular}


The following regression equations are derived from Table 5.

TQu $=234-0.159$ A -0.555 B -1.05 C -0.315 D -0.433 E -0.528 F

$\mathrm{S}=10.4972 \mathrm{R}-\mathrm{Sq}=79.4 \% \mathrm{R}-\mathrm{Sq}(\mathrm{adj})=77.0 \%$

TSt $=364-0.181 \mathrm{~A}-0.869 \mathrm{~B}-1.28 \mathrm{C}-0.370 \mathrm{D}-0.663 \mathrm{E}-0.740 \mathrm{~F}$

$\mathrm{S}=19.6736 \mathrm{R}-\mathrm{Sq}=66.7 \% \mathrm{R}-\mathrm{Sq}(\mathrm{adj})=63.0 \%$

The regression function for $\mathrm{Q}$ is also as follows,

$\mathrm{Q}(\mathrm{Med} 5)=0.0330+0.0638 \mathrm{C}+0.338 \mathrm{~B}+0.0383 \mathrm{E}+0.190 \mathrm{D}+0.0979 \mathrm{~F}+0.124 \mathrm{~A}$

$\mathrm{S}=0.0999849 \mathrm{R}-\mathrm{Sq}=91.8 \% \mathrm{R}-\mathrm{Sq}(\mathrm{adj})=90.4 \%$

The final value of $\mathrm{Q}$ for all cases was identical and did not change. In other words, the interactive factors caused the final level of quality to be limited to a specific value, which was equal to 61 . On the other hand, other groups tended toward their ultimate values. Final and ultimate values in a group were called "balance". Balance occurs when all parts and components in the systems are stable and the mathematical ideal is not equal to 100. Balance in the analysis was achieved for the following final values:

Group A (quality of materials): 68

Group B (performance of involved people (according to law)): 66

Group C (performance of related organizations and institutions (according to law)): 68

Group D (the quantity and quality of legislation and technical documents): 69

Group E (quality of educational and cultural levels): 76

Group F (using industrial construction): 68

Group Q (quality of construction): 61

The other observation is that the final status of the system does not depend on the initial values of the system. Thus, if one or more groups (variables) improved to higher levels, eventually the group interaction experienced a reduction in value and return to their final status. As a result, the optimal level of cost on improving the affected group was to approach balance without exceeding it. However, any change on the relationships and equations could significantly influence the balance which results to either increase or decrease ultimate values. Since the expert feedback equations depend on the current environment of construction, the equations may be affected by future changes in the environment. In Table 2 for instance, A may interact with other parameters as follows,

$$
A(\text { Med5 })=0.0403+0.258 C+0.158 E+0.124 D+0.0898 F+0.110 B+0.121 Z
$$

In the above equation, A depends on B by approximately 11\%. Obviously, this dependency resulted from expert's feedback to the current environment. If the quality of materials is decreased on the market, the relationship will tend to zero. The new situation changes all the relationships and equations in the system and would affect the whole system and the balance as well. As a result, the system dynamic model must be periodically reviewed and the process must be modified based on the logical feedback. The other observation was the impact of changes of $C$ on TQu and TSt. It was observed that, when one group tended toward its ultimate, as A, B, D, E and F reached their final values, the time to achieve TQu and TSt did not change much, although an increase in $\mathrm{C}$ caused a 
greater reduction. This demonstrates the role of $\mathrm{C}$ in the overall model. Other aspects of the influence of $\mathrm{C}$ were:

- When a combination of variables tended toward ultimate values, they created synergy and caused decreases in TQu and TSt. The greatest changes occurred when $\mathrm{C}$ was part of the combination. The compound synergy of groups (e.g., a simultaneous increase in C, E and F) is important for management decisions.

- The more important roles of C and D in the overall model were reflected in the $10 \%$ reduction of a group and when a group approaches zero.

- In cases experiencing a gradual increase and sequential group values that increase from primary to final values, it is important to determine the role of group C. The differences of other groups were tangible on the overall model. The mathematical explanation of this difference will be discussed, subsequently.

A summary of results for TQu, TSt and Q are shown in Tables 6. Although the results are similar but higher values were achieved from R-Sq than TQu regression and the results of TQu are considered as a basis for judgments in subsequent analysis.

\section{Table 6}

The summary of effective groups on TQu, TSt and Q

\begin{tabular}{llllllllllll}
\hline TQu & & \multicolumn{3}{c}{ TSt } & & & & Q & & \\
Group & Value & $\%$ & Rank & Group & Value & $\%$ & Rank & Group & Value & $\%$ & Rank \\
\hline A & 0.159 & 5.2 & 6 & A & 0.181 & 4.4 & 6 & A & 0.124 & 14.6 & 3 \\
B & 0.555 & 18.3 & 2 & B & 0.869 & 21.2 & 2 & B & 0.338 & 39.7 & 1 \\
C & 1.050 & 45.5 & 1 & C & 1.280 & 31.2 & 1 & C & 0.0638 & 7.5 & 5 \\
D & 0.315 & 10.4 & 5 & D & 0.37 & 9.0 & 5 & D & 0.19 & 22.3 & 2 \\
E & 0.433 & 14.2 & 4 & E & 0.663 & 16.2 & 4 & E & 0.0383 & 4.5 & 6 \\
F & 0.528 & 17.4 & 3 & F & 0.740 & 18.0 & 3 & F & 0.0979 & 11.5 & 4 \\
\hline & 3.04 & 100 & & & 4.103 & 100 & & & 0.852 & 100 & \\
\hline
\end{tabular}

A we can observe from Tables 6, the percentage of influence differs clearly for the whole model and for Q. Group C, for instance, had a significant impact of approximately 35\% for the total model, but only $8 \%$ for $\mathrm{Q}$, which is even less than the effects of $\mathrm{A}, \mathrm{B}, \mathrm{D}$ and $\mathrm{F}$. This means that, in managerial assessments, relying on the direct and linear effects of variables on the objective parameters without considering the interactive effects of variables on each other and the whole system, can lead to incorrect decisions. In summary, the influence of $35 \%$ for group $C$ on the whole model means that programs improving the quality of construction should strongly consider the importance and limitations of $\mathrm{C}$ factors, including money and time. This is particularly true when these increases accompany the synergy from a combination of different cases. In other words, C significantly affects other parameters. It is essential, in this context, to focus on the factors of this group. The performance of the housing and urban development ministry, construction engineering organization and Tehran municipality were challenged mainly by country's current and governing codes.

\subsection{Comparison with DEMATEL}

In order to validate the results of our finding from system dynamic we have used DEMATEL technique in this section. Table 7 summarizes the results of the implementation of DEMATEL technique. The most important results of DEMATEL was to determine the effect of different factors on each other and the order of influence based on output parameters of total impact and affectability, $\mathrm{R}+\mathrm{J}$. As we can see from the results, DEMATEL and system dynamic confirm their results. However, the results of the implementation of system dynamic seem to be more realistic. 


\section{Table 9}

The results of the implementation of DEMATEL technique

\begin{tabular}{lllc}
\hline $\begin{array}{l}\text { Sorted based on R+J } \\
\text { Group }\end{array}$ & Value & $\%$ & Ranking \\
\hline A & 5.3339 & 15.1 & 6 \\
B & 6.1351 & 17.4 & 2 \\
C & 6.5972 & 18.7 & 1 \\
D & 5.7643 & 16.4 & 4 \\
E & 5.8753 & 16.7 & 3 \\
F & 5.5314 & 15.7 & 5 \\
\hline
\end{tabular}

\section{Conclusions}

A new methodology for modeling and construction quality analysis in Tehran was presented using a system dynamics model. The proposed model is a causal relationship technique for modeling, analysis and understanding the behavior of complex systems. The case study of this paper gathered the necessary information of 39 factors affecting the quality of private building construction up to five stories in height in Tehran and the groups are divided into six main groups. The information was based on the feedback gathered from experts from different groups. The results of the implementation of system dynamic indicated that group $C$ played an important role on our analysis. In this regard, the performances of the ministry of housing and urban development, construction engineering organization, and Tehran municipality are mainly challenged by experts on the basis of country's current and governing codes.

We have also verified the results of the proposed system dynamic model with DEMATEL technique.

\section{References}

Abdelsalam, H. M. E., \& Gad, M. M. (2009). Cost of quality in Dubai: An analytical case study of residential construction projects. International Journal of Project Management, 27(5), 501-511.

Arditi, D. \& Gunaydin, H. M. (1997). Total quality management in the construction process. International Journal of Project Management, 15(4), 235-243.

Gebremicael, M., Yuan, H., \& Tomsovic, K. (2009). Use of System Dynamics for Studying a Reregulated West African Power Pool, Proceedings of the 2009 IEEE PES General Meeting, Calgary, July 2009.

Fontela, E., \& Gabus, A. (1976). The DEMATEL observer, DEMATEL 1976 report. Switzerland Geneva: Battelle Geneva Research Center.

Leung, S. W., Mak, S., \& Lee, B. L. P. (2008). Using a real-time integrated communication system to monitor the progress and quality of construction works. Automation in Construction, 17(6), 749-757.

Mukherjee, A., Rojas, E. M., \& Winn, W. D. (2005). Understanding cognitive and metacognitive processes in construction management: The system dynamics perspective, Construction Research Congress, doi:10.1061/40754(183)46.

Nasirzadeh, F. Afshar, A., Khanzadi, M. \& Howick, S. (2008). Integrating system dynamics and fuzzy logic modelling for construction risk management, 26(11), 1197 - 1212.

Sterman, J. D. (2000). Business dynamics, systems thinking and modeling for complex world. McGraw-Hill, New Jersey.

Shen, L.Y., Wu, Y. Z., Chan, E. H. W., \& Hao, J.L. (2005). Application of system dynamics for assessment of sustainable performance of construction projects, Journal of Zhejiang University Science, 6A(4), 339-349.

Yi, T., Xiao, G. (2008). Applying system dynamics to analyze the impact of incentive factors' allocation on construction cost and risk. Proceedings of the $7^{\text {th }}$ International Conference on Machine Learning and Cybernetics, Kunming, 12-15.

Zhang, H., \& Xing, F. (2010). Fuzzy-multi-objective particle swarm optimization for time-cost-quality tradeoff in construction. Automation in Construction, 19(8), 1067-1075. 